\title{
The Further Research on the Application of ABC to the Optimization and Control of Project
}

\author{
Cui Qiao ${ }^{1} \&$ Hengshan Wang ${ }^{1}$ \\ ${ }^{1}$ Business School, University of Shanghai for Science and Technology, China \\ Correspondence: Cui Qiao, Business School, University of Shanghai for Science and Technology, No. 334 \\ Jungong Road, Yangpu District, Shanghai, China. Tel: 86-187-0187-9681. E-mail: elinaelina@sina.cn
}

Received: June 3, 2012 Accepted: July 19, 2012 Online Published: October 26, 2012

doi:10.5539/emr.v1n2p96 URL: http://dx.doi.org/10.5539/emr.v1n2p96

This paper is sponsored by the Shanghai key discipline (S30504) and the National Natural Science Foundation of China (71971098).

\begin{abstract}
A new way of optimization has caught many researchers'attention, namely the heuristic algorithms, including Genetic Algorithm (GA), Simulating Algorithm (SA), Particle swarm optimization (PSO), ant colony optimization (ACO), Artificial Bee Colony Algorithm (ABC) and so on. Some ways of the heuristic algorithms belong to swarm intelligent optimizating algoritms such as PSO, ACO and ABC. ABC is the newest of the swarm intelligent optimizating algorithms, which is not developed perfectly and not be fully employed to a variety of fields. The paper introduces $\mathrm{ABC}$ to the optimization of the muli-objective optimization on construction project time-cost-quality and compare the results of $\mathrm{ABC}$ with the results of GA or PSO, which not only optimizes the project, but also proves the effectiveness of $\mathrm{ABC}$, extends the applied fields of $\mathrm{ABC}$ and puts forword a new effective method of optimizing the construction project time-cost-quality.
\end{abstract}

Keywords: Articial Bee Colony Algorithm (ABC), Time-Cost-Quality (TCQ), Multi Attributive Utility function (MAU)

\section{Introducation}

\subsection{Introduce the Problem}

Swarm intelligence has become a research interest to many research scientists of related fields in recent years. Dorigo, inspired by the mechanism of organic evolution, proposed ant colony optimization (ACO) by simulating the foraging behavior of ant colonies. Particle Swarm Optimization (PSO) is a swarm intelligence technique developed by Eberhart and Kennedy who were inspired by the social behavior of bird flocking and fish schooling in 1995. Both ACO and PSO are swarm intelligence. In general, an individual is not intelligent. However, the whole biotic population display the ability to solve the complicated problems. Swarm intelligence is the application of the group behaviors in the field of artificial intelligence.

A numerical function optimization algorithm based on foraging behavior of honey bees, called Artificial Bee Colony (ABC) was proposed by Karaboga (2005). Karaboga and Basturk (2008) draw a conclution that ABC had the same good performance as PSO, Differential Evolution (DE) and Evolutionary Algorithm (EA) by comparing ABC to PSO, EA and DE in solving the five standard functions. Fan and Ma (2010) employ ABC to solve 0-1 knapsack problem. A. M. Bernarino and E. M. Bernarino (2010) applied ABC to the problem of weighted loading ring net. Hu, Zhao and Sa (2009) employs ABC to solve JSP and Hu and Zhao (2009) employ ABC to solve TSP, Sundar and Singh (2010) apply ABC to solve quadratic Minimum Degree Spanning Tree Problem, Hsieh, Hsiao \& Yeh (2011) use ABC to predict the stock price, Karaboga (2009) employs ABC to design digital IIR filters, Kang, Li and Xu (2009) do structural inverse analysis by hybridsimplex ABC, Ho and Shi-you (2009) solve inverse problems by ABC, Hetmaniok, Slota and Zielonk (2010) get solution of the inverseheat conduction problem by using the $\mathrm{ABC}$ algorithm.

\subsection{Explore Importance of the Problem and Describe Relevant Scholarship}

Time, cost, and quality of the project are the three main aims of project management. The optimization of the three 
objectives can come down to the problem of muli-objective optimization. There are few literature balancing time and cost and quality in recent years. McKim, Hegazy and Attalla (2000) put forward that cost, time and quality are the three main guidelines in evaluating the construction project. These indicators are highly relevant and need being balanced. Rwelamila et al. (1995) proposed that project managers usually try to seek the most effective methods of balancing schedule and cost but rarely analyze the significance of quality. Tang and Qin (1998) introduce the model of simulating the control of construction project TCQ and the ways of analyzing risk based on the technique of PERT. Babua and Suresh (1996) and BaKhang and Mon (1999) make linear model of time,quality and cost in the construction of a specific cement plant and evaluate the effectiveness of this model. Wang, Liu and Luo (2004), Yang, Y. L. Wang and N. M.Wang (2006). and Gao, Hu and Zhong (2007) have made mathematical model on time, cost and quality repectively. Kaheled and Amr (2005) put forward the multi-objective model of balancing time, cost and quality.

\subsection{State Hypotheses and Their Correspondence to Research Design}

This paper presents the time-cost-quality tradeoff optimization model using multi-attribute utility (MAU) function theory and applies $\mathrm{ABC}$ to two specific cases based on network planning techniques. Then it compares the results of ABC with the result of GA in Ho and Shi-you (2009) or the result of PSO in (Zhang \& Xing, 2010), which show the results of $\mathrm{ABC}$ is better than the results of GA and PSO. Therefore, it turns out to be that $\mathrm{ABC}$ can obtain the most satisfied decision result and provided a novel and effective way to project managers. In addition, if do many times of experiments, $\mathrm{ABC}$ can often obtain not only one best solution vector, which is beneficial for project managers to make reasonable decision flexiblely according to the specific conditions of project implementation.

\section{Method}

\section{1 $A B C$}

\subsubsection{Bee Clony in Nature}

Bee clony in nature: self-organization and division of labour are necessary and sufficient properties to obtain swarm intelligent behaviour such as distributed problemsolving systems that self-organize and adapt to the given environment:

a) Self-organization can be defined as a set of dynamical mechanisms, which result in structures at the global level of a system by means of interactions among its low-level components. These mechanisms establish basic rules for the interactions between the components of the system. The rules ensure that the interactions are executed on the basis of purely local information without any relation to the global pattern. Bonabeau et al. have characterized four basic properties on which self organization relies: Positive feedback, negative feedback, fluctuations and multiple interactions. Positive feedback is a simple behavioural "rules of thumb" that promotes the creation of convenient structures. Recruitment and reinforcement such as trail laying and following in some ant species or dances in bees can be shown as the examples of positive feedback. Negative feedback counterbalances positive feedback and helps to stabilize the collective pattern. In order to avoid the saturation which might occur in terms of available foragers, food source exhaustion, crowding or competition at the food sources, a negative feedback mechanism is needed. Fluctuations such as random walks, errors, random task switching among swarm individuals are vital for creativity and innovation. Randomness is often crucial for emergent structures since it enables the discovery of new solutions. In general, self organization requires a minimal density of mutually tolerant individuals, enabling them to make use of the results from their own activities as well as others.

b) Division of labour namely simultaneous task performance by cooperating specialized individuals is believed to be more efficient than the sequential task performance by unspecialized individuals and enables the swarm to respond to changed conditions in the search space. The foraging bees are classified into three categories employed, onlookers and scouts. All bees that are currently exploiting a food source are classified as the employed bees. The employed bees bring loads of nectar from the food source to the hive and may share the information about food source with onlooker bees. 'Onlookers' are those bees that are waiting in the hive for the information to be shared by the employed bees about their food sources and 'scouts' are those bees which are currently searching for new food sources in the vicinity of the hive.

\subsubsection{Basic Thought of ABC}

In the beginning of foraging behavior,all the bees have know nothing about the food sources,namely all the bees are scouts who seek randomly food sources near beehives, this stage is like the population initialization in optimizing phase; After a while, half of the bees find food source and become employed bees, the employed bees begin to spread the food information or give up the found food source and become scouts at some rate, the stage is like the stage of seeking feasible solutions in optimizating process, in which stage some solutions don't meet the 
constraint condition will be replaced randomly; Another half bees who haven't found food source become onlookers, the onlookers wait for the food information from employed bees and receive the food information at some probability. The probability is positively correlated to the specific information on food resource(such as sugar content and so on), this stage is like natural selection, the bigger value of fitness is more likely to be received, the received feasible solution can mutate to get the better solution. Later,the onlooker will check if the number of failure time is beyond the limited number, if the number is bigger than the limited ,then gives up the current food source for it is probable to be far away from beehive, this stage is like the verification stage in the optimizing process, in which if the current solution is not easy to be found and then it will be replaced with a new generated solution. Bee colony will not stop repeating the steps above (except the initial stage)until maximum iteration or minimum criteria is attained, it's the same story in the optimizing phase.

The specifications are shown as Figure 1 and Figure 2.

Scouts who seek randomly food source

The employed Bees begin to spread the food information or give up the found food source and become scouts at some rate and record the currently best food source.

\section{$1<$}

The onlookers wait for the food information from employed bees and receive the food information at some probability. Update the currently best food source.

\section{7}

The onlooker will check if the number of failure time is beyond the limited number, if the number is bigger than the limited, then give up the current food source for it is probable to be far away from beehive. Update the currently best food source.

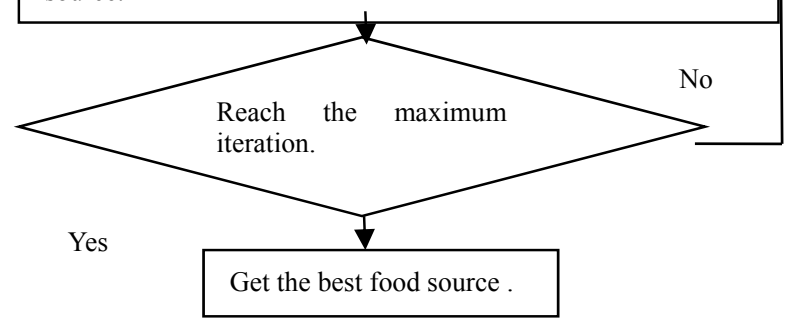

Figure 1. Behaviour characteristics of forager

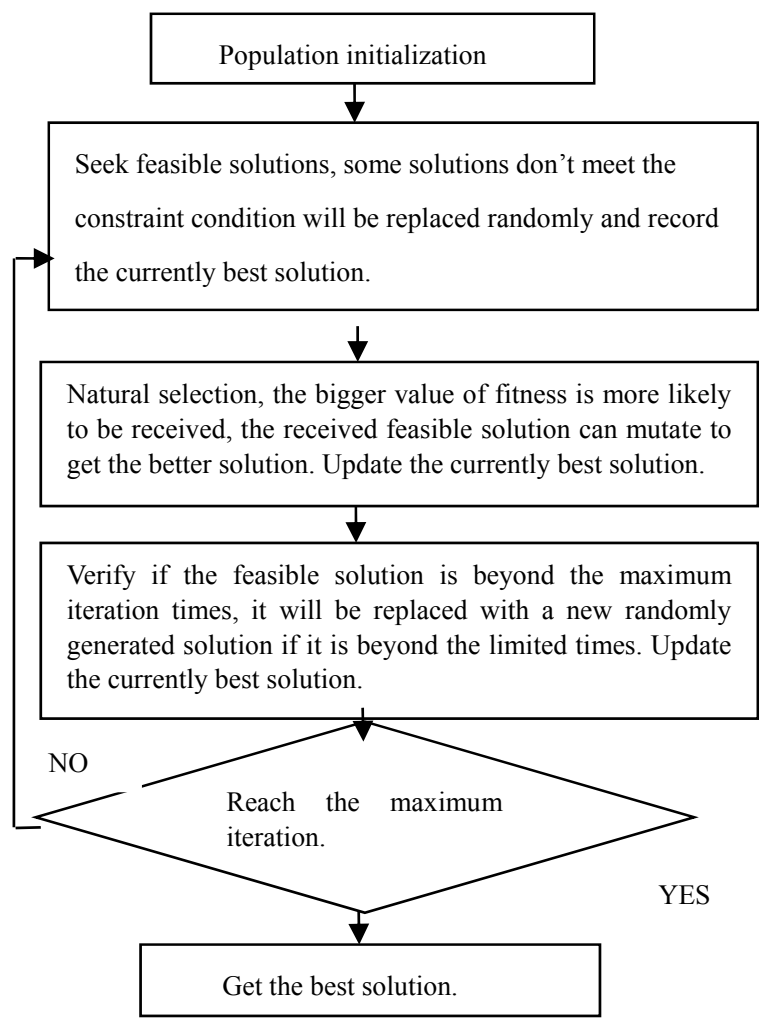

Figure 2. Corresponding optimizating stages

\subsubsection{Detailed Pseudocode of the ABC Algorithm}

1: Initialize the population of solutions $x_{i, j}$;

2: Evaluate the population;

3: cycle $=1$;

4: repeat;

5: Produce new solutions (food source positions) $v_{i, j}$ in the neighbourhood of $x_{i, j}$ for the employed bees using the formula $v_{i, j}=x_{i, j}+\Phi_{i j}\left(x_{i, j}-x_{k, j}\right.$ ) (k is a solution in the neighbourhood of I, $\Phi$ is a random number in the range $[-1,1]$ )and evaluate them;

6: Apply the greedy selection process between $x_{i}$ and $v_{i}$;

7: Calculate the probability values $P_{i}$ for the solutions $x_{i}$ by means of their fitness values using equation (1)

$$
P_{i}=x_{i, j} / \sum_{i=1}^{S N} f_{i}
$$


In order to calculate the fitness values of solutions we employed the following equation (2)

$$
f_{i} t_{i}=\left\{\begin{array}{l}
1 /\left(1+f_{i}\right) \ldots f_{i} \geq 0 \\
1+a b s\left(f_{i}\right) \ldots f_{i}<0
\end{array}\right\}
$$

Normalize $P_{i}$ values into [0,1];

8: Produce the new solutions (new positions) $v_{i}$ for the onlookers from the solutions $x_{i}$, selected depending on $P_{i}$, and evaluate them;

9: Apply the greedy selection process for the onlookers between $x_{i}$ and $v_{i}$;

10: Determine the abandoned solution (source), if exists, and replace it with a new randomly produced solution $x_{i}$ for the scout using the equation (3)

$$
x_{i j}=\min _{j}+\operatorname{rand}(0,1) *\left(\max _{j}-\min _{j}\right)
$$

11: Memorize the best food source position (solution) achieved so far;

12: cycle $=$ cycle +1 ;

13: until cycle $=$ Maximum Cycle Number $(\mathrm{MCN})$.

\subsection{Multiple Attribute Utility of the Project}

\subsubsection{The Basic Principles of Multiple Attribute Utility}

Multiple attribute utility (MAU) which originated in the eighteenth century was developed by Zeng, Jie and Cun (2004). MAU theory is an analytical method for decision-making based on multiple criteria. Applications of MAU in the construction field include the studies on procurement route selection (Chang \& Ive, 2002) and performance assessing of construction engineering.

Attribute utility means a measure of the desirability of outcomes associated with an alternative action. An alternative may be chosen according to the preference of decision-makers or the importance of each single criterion or performance. Each alternative to be evaluated is measured through multiple attribute functions that respectively represent each single criterion and are composed using a series of weights. Such a weight may reflect the preference of decision-makers or the importance of each performance.

If there are $\mathrm{J} \geq 1$ criteria for each alternative, then let $\left(\mathrm{u}_{1}, u_{2}, \ldots, u_{J}\right)$ denote a vector of performances for an alternative, then the composite attribute utility for measuring this alternative can be obtained as (4)

$$
U=\sum_{j=1}^{J} w_{j} u_{j}\{U \in[0,1] ; u j \in[0,1]\}(j=1,2, \ldots J)
$$

Where $u_{j}$ is the single attribute utility function for the performance $\mathrm{j}$ and is scaled from 0 to $1 . w_{j}$ is the weight for the performance $\mathrm{j}$ and the sum of all the weights is equal to 1 , i.e $\sum_{J=1}^{J}{ }^{w} j=1$. The risk neutral utility function is commonly used and is defined as (5)

Where $a_{j}$ and $b_{j}$ are the constants and can be determined based on the best and the worst performances where their measure levels respectively reach the lowest value 0 and the highest value 1 .

\subsubsection{The Method of Creating the Multiple Attribute Utility Function of TCQ}

With regards to the project performances such as time, cost and quality associated with a combination of construction methods, the equations for computing the single utility values for time, cost and quality of a project can be expressed as (6), (7), (8):

$$
u_{T}=\left\{\begin{array}{l}
a+b\left(T-T^{-}\right)^{2} \ldots T \in\left[T^{-}, T^{+}\right] \\
0 \ldots \ldots \ldots \ldots \ldots \ldots T \notin\left[T^{-}, T^{+}\right]
\end{array}\right.
$$




$$
\begin{aligned}
& u_{C}=\left\{\begin{array}{l}
c+d\left(C-C^{-}\right)^{2} \ldots C \in\left[C^{-}, C^{+}\right] \\
0 \ldots \ldots \ldots \ldots \ldots \ldots \ldots\left[C^{-}, C^{+}\right]
\end{array}\right. \\
& u_{Q}=\left\{\begin{array}{l}
e+f\left(Q-Q^{-}\right)^{2} \ldots Q \in\left[Q^{-}, Q^{+}\right] \\
0 \ldots \ldots \ldots \ldots \ldots \ldots \in\left[Q^{-}, Q^{+}\right]
\end{array}\right.
\end{aligned}
$$

Where T, C and Q respectively represent the time, cost and quality of a project. $T^{+}$and $T^{-}$respectively represent the longest and shortest project durations; $C^{+}$and $C^{-}$respectively represent the maximum and minimum total cost; $Q^{+}$and $Q^{-}$respectively represent the maximum and minimum overall quality of a project. If the weights for the three performances are $w_{T}, w_{C}$ and $w_{Q}$ respectively, then the composite attribute utility can be obtained through (9)

$$
U=w_{T} u_{T}+{ }^{+}{ }_{C}{ }_{C}+w_{Q}{ }^{u} Q
$$

The optimal alternative should be the one that has the largest composite attribute utility.

\section{The Introduction of Two Specific Cases and the Creation of Their MAU Functions}

\subsection{The Creation of the Multiple Attribute Utility Function of Specific Case I}

3.1.1 The Introduction of the Specific Case I

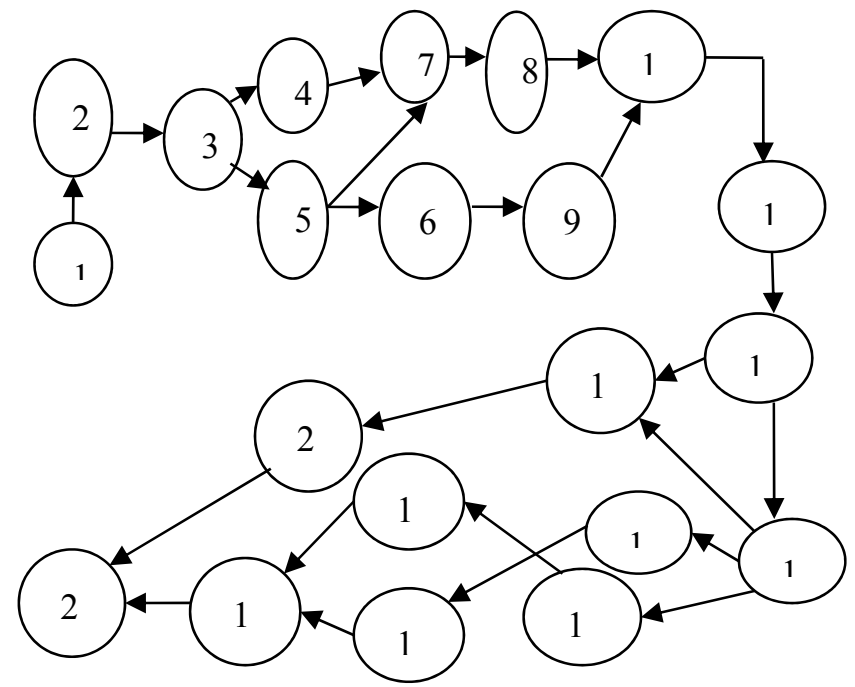

Figure 3. The Network-planning diagram

Table 1. Specific parameters

\begin{tabular}{lllllllllll}
\hline Jname & $\begin{array}{l}\text { Activity } \\
\text { number }\end{array}$ & Activity name & $\begin{array}{l}\text { back } \\
\text { closely } \\
\text { activity }\end{array}$ & & $\begin{array}{l}\mathrm{T}+\mathrm{d}- \\
\mathrm{d}\end{array}$ & $\begin{array}{l}\mathrm{C}+ \\
\text { yuan }\end{array}$ & $\begin{array}{l}\mathrm{C}- \\
\text { yuan }\end{array}$ & $\begin{array}{l}\mathrm{Q}+ \\
\%\end{array}$ & $\begin{array}{l}\mathrm{Q}- \\
\%\end{array}$ & $\mathrm{w}_{\mathrm{Q}}$ \\
\hline $\mathrm{A}$ & 1 & preliminary work & 2 & 0 & 0 & 0 & 0 & 0 & 0 & 0 \\
$\mathrm{~B}$ & 2 & foundation & 3 & 24 & 20 & 110527 & 154608 & 1 & 0.9233 & 0.0875 \\
$\mathrm{C}$ & 3 & $\begin{array}{l}\text { Wall in the first } \\
\text { floor }\end{array}$ & $4 、 5$ & 18 & 15 & 85563 & 119788 & 1 & 0.9133 & 0.0772 \\
$\mathrm{D}$ & 4 & $\begin{array}{l}\text { beam and slab in the } \\
\text { first floor }\end{array}$ & 7 & 30 & 25 & 135581 & 189816 & 1 & 0.9156 & 0.0637 \\
$\mathrm{E}$ & 5 & $\begin{array}{l}\text { Stairs betwee the } \\
\text { first and second } \\
\text { floor }\end{array}$ & $6 、 7$ & 13 & 12 & 9867 & 13813 & 1 & 0.8889 & 0.0557 \\
& & & & & & & & \\
\hline
\end{tabular}




\begin{tabular}{|c|c|c|c|c|c|c|c|c|c|c|}
\hline $\mathrm{F}$ & 6 & $\begin{array}{l}\text { cast-in-situ in the } \\
\text { first floor }\end{array}$ & 9 & 7 & 5 & 9762 & 13667 & 1 & 0.8700 & 0.0356 \\
\hline G & 7 & $\begin{array}{l}\text { Wall in the second } \\
\text { floor }\end{array}$ & 8,9 & 18 & 15 & 85563 & 119788 & 1 & 0.9033 & 0.0678 \\
\hline $\mathrm{H}$ & 8 & $\begin{array}{l}\text { Beam and slab in } \\
\text { the second floor }\end{array}$ & 10 & 30 & 25 & 135581 & 189816 & 1 & 0.8989 & 0.0609 \\
\hline I & 9 & $\begin{array}{l}\text { Stairs between the } \\
\text { second and third } \\
\text { floor }\end{array}$ & 10 & 13 & 12 & 9867 & 13813 & 1 & 0.8789 & 0.0533 \\
\hline $\mathrm{J}$ & 10 & $\begin{array}{l}\text { Wall in the third } \\
\text { floor }\end{array}$ & 11 & 20 & 16 & 100003 & 140007 & 1 & 0.8956 & 0.0661 \\
\hline K & 11 & $\begin{array}{l}\text { Beam and slab in } \\
\text { the third floor }\end{array}$ & 12 & 30 & 25 & 135581 & 189816 & 1 & 0.8744 & 0.0594 \\
\hline $\mathrm{L}$ & 12 & roof & 13、 19 & 11 & 8 & 63315 & 88641 & 1 & 0.8822 & 0.0476 \\
\hline M & 13 & $\begin{array}{l}\text { Doors windows and } \\
\text { decorations in the } \\
\text { first floor }\end{array}$ & $14 、 15$ & 13 & 9 & 67997 & 95195 & 1 & 0.8600 & 0.0316 \\
\hline $\mathrm{N}$ & 14 & $\begin{array}{l}\text { facilities installation } \\
\text { in the first floor }\end{array}$ & 16、 17 & 4 & 2 & 15062 & 21086 & 1 & 0.8922 & 0.0508 \\
\hline $\mathrm{O}$ & 15 & $\begin{array}{l}\text { Doors windows and } \\
\text { installation in the } \\
\text { second floor }\end{array}$ & 16、 17 & 13 & 9 & 65332 & 91464 & 1 & 0.8689 & 0.0331 \\
\hline $\mathrm{P}$ & 16 & $\begin{array}{l}\text { Facilities } \\
\text { installation in the } \\
\text { second floor }\end{array}$ & 18 & 4 & 2 & 15062 & 21086 & 1 & 0.8878 & 0.0523 \\
\hline Q & 17 & $\begin{array}{l}\text { Doors windows and } \\
\text { installations in the } \\
\text { third floor }\end{array}$ & 18 & 13 & 9 & 65332 & 91464 & 1 & 0.8700 & 0.0338 \\
\hline $\mathrm{R}$ & 18 & $\begin{array}{l}\text { Facilities } \\
\text { installation in the } \\
\text { third floor. }\end{array}$ & 21 & 4 & 2 & 15062 & 21086 & 1 & 0.8856 & 0.0509 \\
\hline $\mathrm{S}$ & 19 & $\begin{array}{l}\text { External wall } \\
\text { decoration }\end{array}$ & 20 & 16 & 12 & 56246 & 79342 & 1 & 0.8644 & 0.0367 \\
\hline $\mathrm{T}$ & 20 & $\begin{array}{l}\text { Steps water apron } \\
\text { and so on }\end{array}$ & 21 & 5 & 3 & 5505 & 7708 & 1 & 0.8700 & 0.0360 \\
\hline $\mathrm{U}$ & 21 & Final end & - & 0 & 0 & 0 & 0 & 0 & 0 & 0 \\
\hline
\end{tabular}

The network-planning diagram is shown as Figure 3, specific parameters are shown as Table1.

3.1.2 The Creation of MAU Function of Case I

$T^{+}=224, C^{+}=1662004, Q^{+}=1, T^{-}=178, C^{-}=1186808, Q^{-}=0.8931$, take them into (10), (11), (12), get $\mathrm{a}=1 \mathrm{~b}=(1 / 46)^{2}, \mathrm{c}=1, \mathrm{~d}=(1 / 475196)^{2}, \mathrm{e}=0, \mathrm{f}=(1 / 0.1087)^{2}$

$$
\begin{aligned}
& u_{T}=\left\{\begin{array}{l}
a+b\left(T-T^{-}\right)^{2} \ldots T \in\left[T^{-}, T^{+}\right] \\
0 \ldots \ldots \ldots \ldots \ldots \ldots T \notin\left[T^{-}, T^{+}\right]
\end{array}\right. \\
& u_{C}=\left\{\begin{array}{l}
c+d\left(C-C^{-}\right)^{2} \ldots C \in\left[C^{-}, C^{+}\right] \\
0 \ldots \ldots \ldots \ldots \ldots \ldots \ldots\left[C^{-}, C^{+}\right]
\end{array}\right.
\end{aligned}
$$




$$
\begin{gathered}
u_{Q}=\left\{\begin{array}{l}
e+f\left(Q-Q^{-}\right)^{2} \ldots Q \in\left[Q^{-}, Q^{+}\right] \\
0 \ldots \ldots \ldots \ldots \ldots \ldots Q\left[Q^{-}, Q^{+}\right.
\end{array}\right. \\
U=w_{T} *\left[1-((T-178) / 46)^{2}\right]+w_{C} *\left[1-((c-1186808) / 475196)^{2}\right]+\left[1-w_{Q} *((Q-1) / 0.1087)^{2}\right]
\end{gathered}
$$

While $w_{T}, w_{C}$ and $w_{Q}$ is calculated by experts grading method, they respectively are $w_{T}=0.3, w_{C}=0.4$ and $w_{Q}=0.3$, take them into (13) and get (14)

$$
U=1-\left[0.3 *((T-178) / 46)^{2}+0.4 *((C-1186808) / 475196)^{2}+0.3 *((Q-1) / 0.1087)^{2}\right]
$$

\subsection{The Creation of the Multiple Attribute Utility Function of Specific Case II}

3.2.1 The Introduction of the Specific Case II

The network-planning diagram is shown as Figure 4, specific parameters are shown as Table 2.

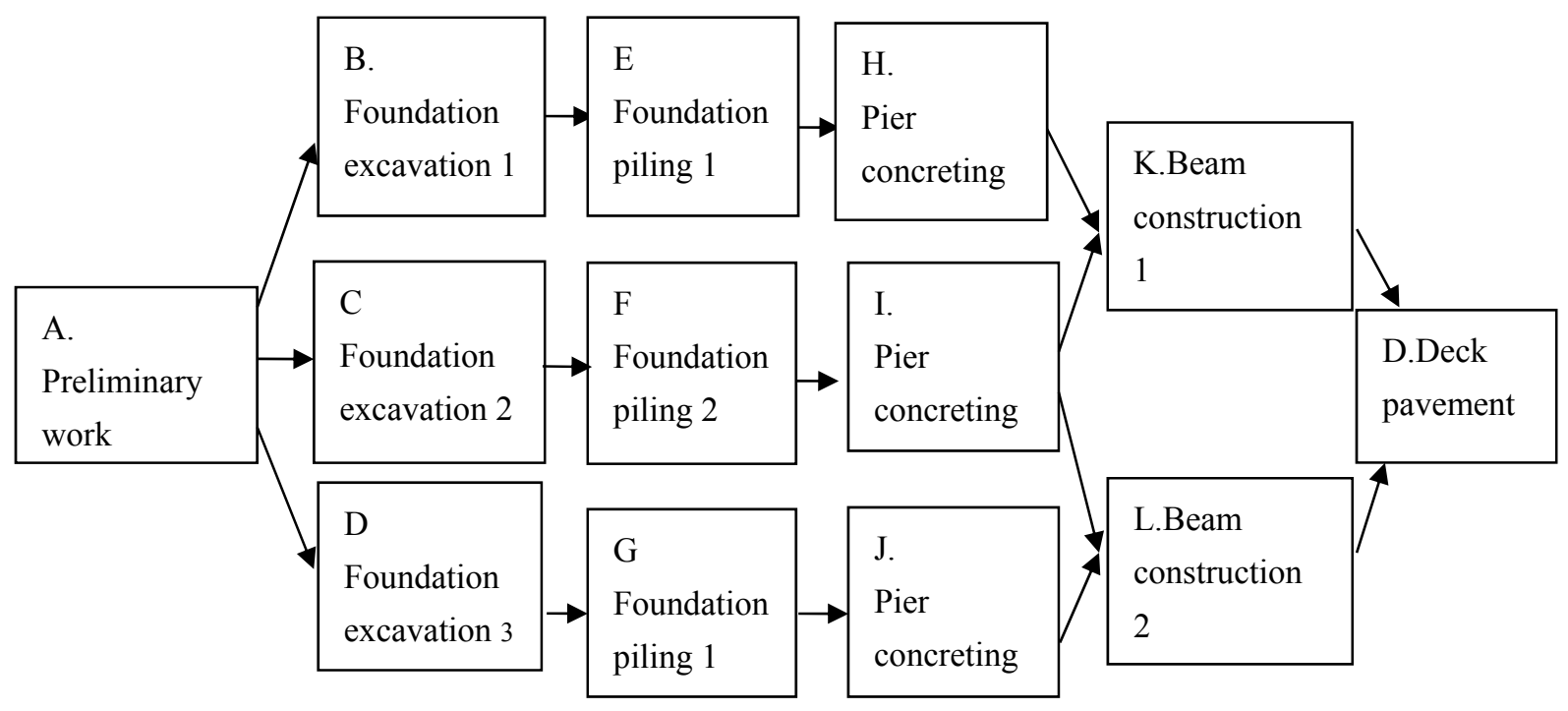

\begin{tabular}{|c|c|c|c|c|c|c|c|c|c|}
\hline $\begin{array}{l}\text { Activity } \\
\text { number }\end{array}$ & Jname & $\begin{array}{l}\text { Activity } \\
\text { name }\end{array}$ & $\mathrm{T}+\mathrm{d}$ & T- $\quad d$ & $\begin{array}{l}\mathrm{C}- \\
\text { yuan }\end{array}$ & $\begin{array}{l}\mathrm{C}+ \\
\text { yuan }\end{array}$ & $\begin{array}{l}\mathrm{Q}^{+} \\
\%\end{array}$ & $\begin{array}{l}\text { Q- } \\
\%\end{array}$ & $\mathrm{w}_{\mathrm{Q}}$ \\
\hline 1 & A & Preliminary work & 26 & 30 & 416 & 600 & 1 & 0.9 & 0.01 \\
\hline 2 & B & Foundation excavation 1 & 40 & 46 & 6400 & 8280 & 1 & 0.9 & 0.08 \\
\hline 3 & $\mathrm{C}$ & Foundation excavation 2 & 40 & 50 & 6600 & 9250 & 1 & 0.9 & 0.09 \\
\hline 4 & $\mathrm{D}$ & Foundation excavation 3 & 39 & 49 & 6240 & 8820 & 1 & 0.9 & 0.08 \\
\hline 5 & E & Foundation piling 1 & 36 & 40 & 4464 & 5760 & 1 & 0.9 & 0.11 \\
\hline 6 & $\mathrm{~F}$ & Foundation piling 2 & 46 & 54 & 8280 & 10800 & 1 & 0.9 & 0.11 \\
\hline 7 & G & Foundation piling 3 & 38 & 42 & 4940 & 6300 & 1 & 0.9 & 0.11 \\
\hline 8 & $\mathrm{H}$ & Pier concreting 1 & 83 & 87 & 17430 & 20010 & 1 & 0.7 & 0.08 \\
\hline 9 & I & Pier concreting 2 & 87 & 93 & 20010 & 23250 & 1 & 0.7 & 0.08 \\
\hline 10 & $\mathrm{~J}$ & Pier concreting 3 & 83 & 87 & 18260 & 20880 & 1 & 0.7 & 0.08 \\
\hline 11 & $\mathrm{~K}$ & Beam construction 1 & 18 & 22 & 1980 & 2860 & 1 & 0.9 & 0.06 \\
\hline 12 & $\mathrm{~L}$ & Beam construction 2 & 20 & 24 & 2400 & 3360 & 1 & 0.9 & 0.06 \\
\hline 13 & M & Deck pavement & 22 & 28 & 1298 & 1988 & 1 & 0.9 & 0.05 \\
\hline
\end{tabular}

Figure 4. The Network-planning diagram

Table 2. Specific parameters 
3.2.2 The Creation of MAU Function of Case II

$T^{+}=279, C^{+}=122158, Q^{+}=1, T^{-}=215, C^{-}=98718, Q^{-}=0.852$.

Take the data in to $(10) \sim(12)$, get $a=1, b=1 / 64, c=1, d=1 / 23340, e=0, f=1 / 0.148$

$$
U=w_{T} *\left[1-((T-215) / 64)^{2}\right]+w_{C} *\left[1-((C-98718) / 23340)^{2}\right]+\left[1-w_{Q} *((Q-1) / 0.148)^{2}\right]
$$

While $w_{T}, w_{C}$ and $w_{Q}$ is calculated by experts grading method, they respectively are $w_{T}=0.3, w_{C}=0.4$ and $w_{Q}=0.3$, take them into (15), get (16)

$$
U=1-\left[0.3 *((T-215) / 64)^{2}+0.4 *((C-98718) / 23340)^{2}+0.3 *((Q-1) / 0.148)^{2}\right]
$$

\section{The Application of $\mathrm{ABC}$ to the Two Cases}

\subsection{The Application of ABC to Optimize the Specific Case 1}

\subsubsection{The Choice of Parameter}

The number of population namely $\mathrm{NP}=20$;

The number of food source namely Foodnumber=10;

The maximum times of failure namely Limit $=100$;

The maximum cycling times nameyMax $=500$;

The number of parameters: $\mathrm{D}=60$;

The lower bound namely

Lb:[0,20,15,25,12,5,15,25,12,16,25,8,9,2,9,2,12,3,0,110527,85563,135581,9867,9762,85563,135581,9867,1000 $03,135581,63315,67997,15062,65332,15062,56246,5505,0,0.9233,0.9133,0.9156,0.8889,0.8700,0.9033,0.8989$, $0.8789,0.8956,0.8744,0.8822,0.8600,0.8922,0.8689,0.8878,0.8700,0.8856,0.8644,0.8700]$

The upper bound namely $\mathrm{Ub}=[0,24,18,30,13,7,18,30,13,20,30,11,13,4,13,4,13,4,16,5,0,154608,119788,189816,13813,13667,119788,1898$ $16,13813,140007,189816,88641,95195,21086,91464,21086,91464,21086,79342,7708,0,1,1,1,1,1,1,1,1,1,1,1,1,1$, $1,1,1,1,1,1]$

4.1.2 The result of experiment and the analysis of the result

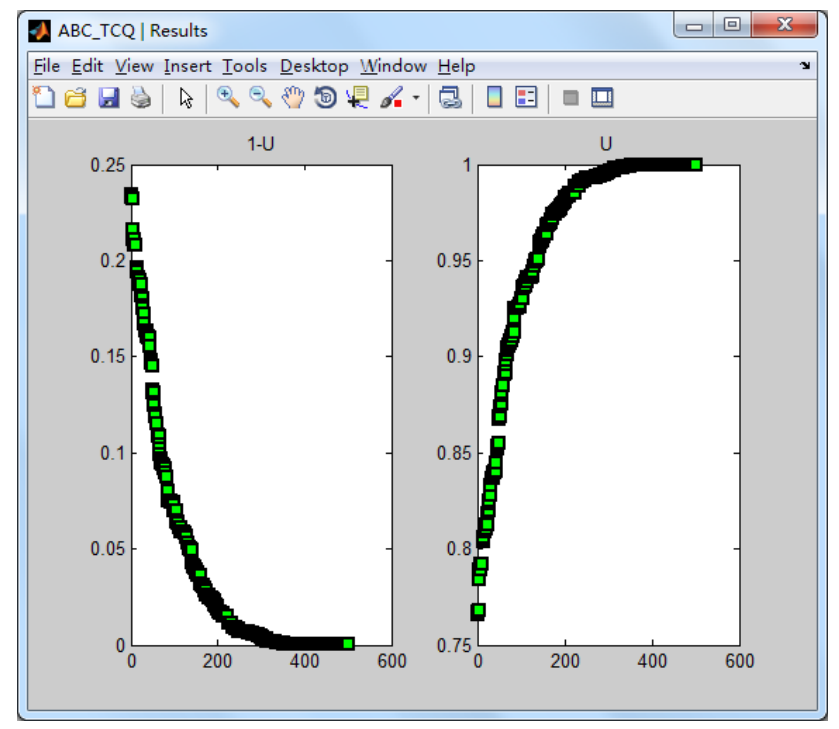

Figure 5. The result of $\mathrm{ABC}$ algorithms 
The result of experiment is shown as Figure 5 When maximum iteration is equal to 500 , the maximum utility is 1 , the best solution vector is not unique, one of them is as follows:

$[0,20,15,25,12.5053,6.3985,15,25,8,9,3.4113,9,3.7384,9,2,13.5524,3.3389,0,110527,85563,135581,9867,9762,8$ $5563,135581,9867,100003,135581,63315,67997,15062,65332,15062,65332,15062,56246,5505,0,1,1,1,1,1,1,1,1$, $1,1,1,1,1,1,1,1,1,1,1,1]$

$\mathrm{T}=178 ; \mathrm{C}=1186808 ; \mathrm{Q}=1$

4.1.3 The Analysis of the Result

Table 3. The analysis of the results

\begin{tabular}{lll}
\hline Best solutions & \multicolumn{2}{l}{ The maximum utility } \\
\cline { 2 - 3 } & $A B C$ & GA in(Ho\& Shi-you,2009) \\
values & 1 & 0.8480 \\
\hline
\end{tabular}

The results of various algorithms is in Table 3. Compare optimal solution of the $\mathrm{ABC}$ algorithm to GA in (Ho \& Shi-you, 2009), we can see that the solution quality of ABC algorithm is better and robuster than the optimum solutions of GA algorithm.

\subsection{The Application of ABC to Optimize the Specific Case II}

\subsubsection{The Choice of Parameter}

The number of population namely $\mathrm{NP}=20$;

The number of food source namely Foodnumber=10;

The maximum times of failure namely Limit $=100$;

The maximum cycling times nameyMax $=2500$;

The number of parameters: $\mathrm{D}=39$.

The lower bound namely $\mathrm{L} b=[26,40,40,39,36,46,38,83,87,83,18,20,22,416,6400,6600,6240,4464,8280,4940,17430,20010,18260,1980,24$ $00,1298,0.9,0.9,0.9,0.9,0.9,0.9,0.9,0.7,0.7,0.7,0.9,0.9,0.9]$

The upper bound namely $\mathrm{Ub}=[30,46,50,49,40,54,42,87,93,87,22,24,28,600,8280,9250,8820,5760,10800,6300,20010,23250,20880,2860,3$ $360,1988,1,1,1,1,1,1,1,1,1,1,1,1,1]$

4.2.2 The result of experiment

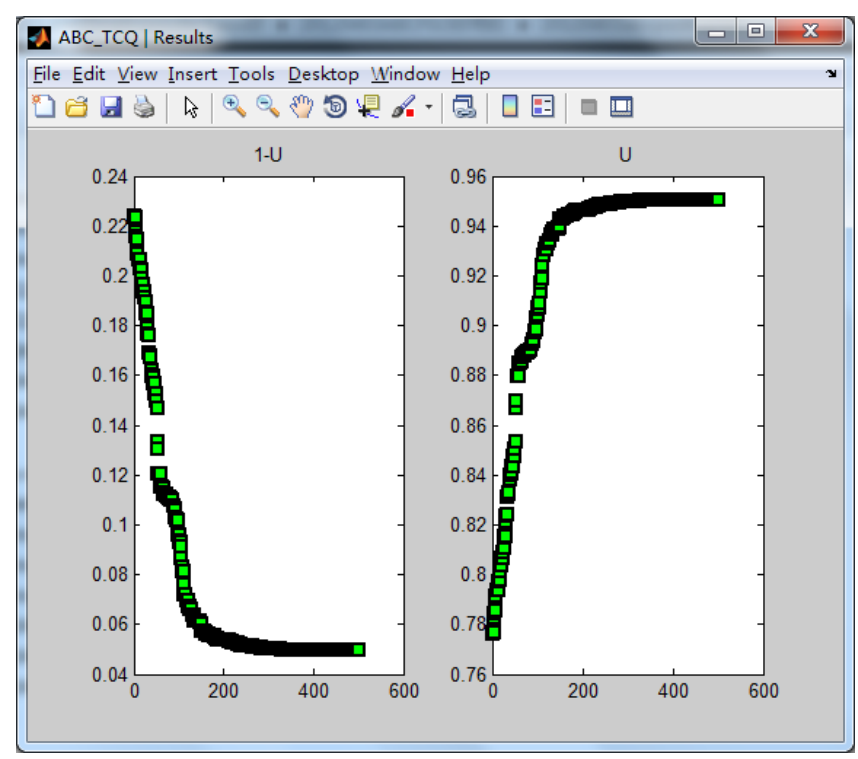

Figure 6. The result of $\mathrm{ABC}$ algorithms 
Table 4. The analysis of the results

\begin{tabular}{lll}
\hline Best solutions & The maximum utility & \\
& $A B C$ & PSO in (Zhang\&Xing, 2010) \\
\hline values & 0.9504883 & 0.906 \\
\hline
\end{tabular}

The result of experiment is shown as Figure 6. When maximum iteration is equal to 2500 , the maximum utility is 0.9504883, the best solution vector is not unique, one of them is as follows:

$[26,42,40,40,39,46,40,87,87,83,19,20,22,416,6400,6600,6240,4464,8280,4940,17430,20010,18260,1980,2400,1$

$298,1,1,1,1,1,1,1,1,1,1,1,1,1]$

$\mathrm{T}=241 ; \mathrm{C}=100260 ; \mathrm{Q}=1$

4.2.3 The Analysis of the Result

The results of various algorithms is in Table 3, Compare optimal solution of the ABC algorithm to PSO in (Zhang \& Xing, 2010), we can see that the solution quality of ABC algorithm is better and robuster than the optimum solutions of GA algorithm.

\section{Discussion and Conclusion}

This paper presents the time-cost-quality tradeoff optimization model using multi-attribute utility (MAU) function theory and applies $\mathrm{ABC}$ to two specific cases based on network planning techniques. Then it compares the results of ABC with the result of GA in (Ho \& Shi-you, 2009)or the result of PSO in (Zhang \& Xing, 2010), which not only show the results of ABC is better than the results of GA and PSO but also display the robustness of ABC. In conclusion, the paper not only proves the effectiveness of $A B C$, extends the applied fields of $A B C$, but also puts forword a new effective method for project managers to optimize the construction project time-cost-quality.

\section{Acknowledgements}

I am most indebted to my teacher Hengshan Wang, who has spent much of her precious time in offering valuable advice and guidance in my writing, and whose intellectual insights have contributed greatly to the completion of this thesis. Had he not devoted his painstaking efforts to reading patiently each draft and making critical comments, the completion of this thesis would have been impossible.

My special thanks also go to all my teachers whose inspiring lectures have had an undoubted influence on much of the content of my thesis. I would like to extend my heartfelt gratitude to the authors whose words I have cited or quoted, and to the scholars upon whose ideas I have freely drawn.

\section{References}

Babu, A. J. G., \& Suresh, N. (1996). Project management with time, cost, and quality considerations. European Journal of Operational Re-search, 88(2), 320-327. http://dx.doi.org/10.1016/0377-2217(94)00202-9

BaKhang, D., \& Mon, M. Y. (1999). Time, cost and quality trade_offinproject management: A case study. $\begin{array}{llll}\text { International Journal of Project Management, } & \text { 17(4), 249-256. }\end{array}$ http://dx.doi.org/10.1016/S0263-7863(98)00043-X

Bernarino, A. M., Bernarino, E. M., \& Sanchez-perez, J. M. (2010). Efficient load balancing for a resilient packet ring using artificialbee colony. Evolutionary Applications, 6025(2), 61-70.

Chang, C. Y., \& Ive, G. (2002). Rethinking the multi-attribute utility approach based procurement route selection technique. Construction Management and Economics, 20, 275-284. http://dx.doi.org/10.1080/01446190110117608

Fan, X. M., \& Ma, L. (2010). Atificial Bee colony algorithm for 0-1 Knapsack Problem. Mathematics in Practice and Theory, 40(6), 155-160.

Gao, X. F., Hu, C. S., \& Zhong, D. H. (2007). Study Synthesis Optimization of Time-Cost-Quality in Project Management. Systems Engineering-Theory\&Practice, 27(7), 112-117.

Hetmaniok, E., Slota, D., \& Zielonk, A. A. (2010). Solution of the inverseheat conduction problem by using the ABC algorithm. Berlin: Springer-Verlag.

Ho, S. L., \& Shi-you, Y. (2009). An artificial bee colony algorithm for inverse problems. International Journal of Applied Electromagneticsand Mechanics, 31(3), 181-192. 
Hsieh, T. J., Hsiao, H, F., \& Yeh, W. C. (2011). Forecasting stock markets using wavelet transforms and recurrent neural networks: an integrated system based on artificial bee colony algorithm. Applied Soft Com-putting, 11(2), 2510-2525. http://dx.doi.org/10.1016/j.asoc.2010.09.007

Hu, Z. H., \& Zhao, M. (2009). Simulation on Traveling Salesman Problem (TSP) Based on Artificial Bees Colony Algorithm. Transactions of Beijing Institute of Technology, 29(11), 978-982.

Hu, Z. H., Zhao, M., \& Sa, P. F. (2009). A Simulation Study of Job Shop Scheduling Using Artificial Bees Colony Algorithm. Mechanical Science and Technology for Aerospace Engineering, 28(7), 851-856.

Kaheled, E., \& Amr, K. (2005). Time-cost-quality trade-off analysis for highway construction. Journal of $\begin{array}{llll}\text { Construction Engineering and } & \text { 477-485. }\end{array}$ http://dx.doi.org/10.1061/(ASCE)0733-9364(2005)131:4(477)

Kang, F., Li, J. J., \& Xu, Q. (2009). Structural inverse analysis by hybridsimplex artificial bee colony algorithms. Computers and Struc-tures, 87(13-14), 861-870. http://dx.doi.org/10.1016/j.compstruc.2009.03.001

Karaboga, D. (2005). An Idea Based On Honey Bee Swarm for Numerical Optimization. Kayseri Turkey: Erciyes University.

Karaboga, D., \& Basturk, B. (2008). On the performance of Atificial of Bee Colony (ABC) algorithm. Applied Soft Computing, 8(1), 687-697. http://dx.doi.org/10.1016/j.asoc.2007.05.007

Karaboga, N. (2009). A new design method based on artificial bee colony algorithm for digital IIR filters. Journal of the Franklin Institute-Engineering and Applied Mathematics, 346(4), 328-348. http://dx.doi.org/10.1016/j.jfranklin.2008.11.003

McKim, R., Hegazy, T., \& Attalla, M. (2000). Project performance control in reconstruction projects. Journal of $\begin{array}{llll}\text { Construction Engineering and } & \text { 126(2), } & \text { 137-141. }\end{array}$ http://dx.doi.org/10.1061/(ASCE)0733-9364(2000)126:2(137)

Rwelamila, P. D. et al. (1995). Total systems intervention: An integrated approach to time, cost and quality management. Construction Management and Economics, 13, 235-241. http://dx.doi.org/10.1080/01446199500000027

Sundar, S., \& Singh, A. A. (2010). Swarm intelligence approach to the quadraticminimum spanning tree problem. Information Sciences, 180(17), 3182-3191. http://dx.doi.org/10.1016/j.ins.2010.05.001

Tang, D. F., \& Qin, D. J. (1998). Analogy system for controlling quality time cost of construction projects. Journal of Shenyang Architectural and Civil Engineering Institute, 14(2), 158-161.

Wang, J., Liu, E. L., \& Luo, G. (2004). Analysis of time-cost-quality trade off optimization in construction project managemeng. Journal of Systemw Engineering, 19(2), 148-153.

Yang, Y. H., Wang, Y. L., \& Wang, N. M. (2006). Fuzzy Tradeoff Optimization of Time-Cost-Quality inConstruction Project. Systems Engineering-Theory \& Practice, 26(7), 112-117.

Zhang, H., \& Xing, F. (2010). Fuzzy-multi-objective particle swarm optimization for time-cost-quality tradeoff in construction. Automation in Construction, 19, 1067-1075. http://dx.doi.org/10.1016/j.autcon.2010.07.014

Zeng, J. C., Jie, Q., \& Cun, Z. H. (2004). Particle Swarm Optimization. Academic Press Inc. 